The Turkish Online Journal of Design, Art and Communication - TOJDAC July 2016 Special Edition

\title{
THE EVOLUTION OF THE COOKHOUSE TO THE KITCHEN
}

\author{
Hooman Sobouti \\ Department of Architecture, Zanjan Branch, Islamic Azad University, Zanjan, Iran \\ Young Researchers and Elites Club, Zanjan Branch, Islamic Azad University, Zanjan, Iran \\ hoomansobouti@,znu.ac.ir \\ Ali Ghasemi \\ Department of Architecture, Zanjan Branch, Islamic Azad University, Zanjan, Iran \\ ali.qasemi1985@gmail.com
}

\begin{abstract}
Throughout history architecture has undergone significant changes including the interior space of houses; however, in this regard, the design of the kitchen space has had an outstanding progress. The cookhouse which in the pattern of the traditional houses was always situated in the yard or the basement, has constantly been regarded as a secondary space; but after some development it has been situated next to the guest room and the bedrooms thus leading to the modern life comfort. In this paper which is both descriptive and analytical, the evolution of the cookhouse to the kitchen during the last century is studied. Also the role of the technology in altering a secondary space (a cookhouse) to a main multi-purpose space (a kitchen) is investigated.
\end{abstract}

Keywords: cookhouse, kitchen, technology, evolution, the design of the traditional house

\section{INTRODUCTION}

A cookhouse in the Iranian traditional architecture, in the process of the design of an Iranian house, was built in the yard and its only means of access was through the central yard; and it was next to the interior and the exterior parts of the house. The openings in its ceiling were used for ventilation of smoke that was usually made by the burning of desert plants and the animal waste. Before the $18^{\text {th }}$ century, there was no concept as a kitchen in the structure of man's living space. The stove was a place for fire, a place that provided the warmth for living and cooking. This place due to its usefulness was special and it was regarded as a distinctive feature of a living space. Gradually, through the evolvement of living conditions, with the goal of providing comfort, places were added to the basement or yards known as cookhouse that had a number of stoves and ovens for cooking (Ghaderi, 2012). In recent years because of the smallness of apartments we face open system kitchens. In fact, this structural change has become a fashion in the interior architecture. Nevertheless, this expression is applicable to the kitchen only when it provides an easy visual communication with its nearby spaces. Usually, this happens when a separating wall is removed or the kitchen and its nearby spaces are unified. However, this change like other changes has its advantages and its disadvantages. Today the open system kitchen can nearly be seen in every house across the country, disregarding the architecture of that region and the social and cultural conditions of its inhabitants. An important disadvantage of these kitchens are their conflict with the privacy system of the space of the house. Family privacy was the main function of the traditional houses. However, in the present time, privacy is sacrificed for economic and social functions. The priority for establishment of spaces that preserves privacy is gradually reduced. The effects and results of those spatial relationships is now gone (HaeriMazandarani, 2009). The transference of the cookhouse from the basement of historical houses to the spatial system of modern houses next to the living room and the bedroom is a significant change in the process of providing comfort and convenience of the modern life (HaeriMazandarani,

Submit Date: 10.05.2016, Acceptance Date: 25.06.2016, DOI NO: 10.7456/1060JSE/027 
The Turkish Online Journal of Design, Art and Communication - TOJDAC July 2016 Special Edition

2009). With the new technologies of gas distribution and the usage of municipal tap water, a new space has entered the traditional Iranian architecture and the spatial Iranian housing system. Now it can be said that the kitchen is the beating heart of a house and a place of gathering and family discussions. The modern kitchen is a considerable place for family members and it is a place for daily chores other than cooking (Baden-Powell 2009).

\section{NECESSITY AND OBJECTIVES}

The kitchen is a major public space for the social communication of family members in one place and time. This space can be put to further review and this prompted us to have a close look at this space and to study the evolvement of the cookhouse as a secondary space in the yard, to the modern concept of the kitchen as the beating heart of the house. Since this space is used for family gatherings, discussions and important decisions, in this paper we study the evolvement of this space in recent decades.

\section{A REVIEW OF THE MEANING OF THE COOKHOUSE}

In Dictionary of Dehkhoda, a cookhouse is defined as a place for cooking, a kitchen, a place for the cooking pot, BawerchiKhaneh, a home cooking pot and Khorushkhaneh. Examples from Tarikh-i Bayhaqi, Mawlawi's poems, khaqani, Nizami and other poets and writers show that the word cookhouse has the same meaning.

Dehkhoda defines a kitchen as: a cookhouse, an oven home, Ashkhaneh, BawerchiKhaneh. For him cookery is equivalent of cooking, Khaligari, pot cooking, food making, Tabakht and KhordehPazi.

\section{THE COOKHOUSE}

In the historical houses, cookhouses (kitchens) were usually located away from the living rooms and were aligned with the basement or the space between the main structure, adjacent to the yard and the corners of the house. For the entrance of light and air there were one or more openings on its ceiling. Also it had shelves made by the building materials that include counters and a storage space for storing fuel and cooking materials and utensils. In comparison with modern kitchens, Lack of light, ventilation and smoke were among the disadvantages of these spaces (HaeriMazandarani, 2009). Compared to the main space of the house and the rooms, the cookhouse was usually dark and at night some lamps were used for providing light. Its floor was made of brick or stone with no mat or rug. Every cookhouse had two key factors related to cooking: the oven and the stove. The oven was usually built on one side of the cookhouse and was used for baking bread. However, sometimes it was also used for cooking and warming food, in such a way that a tripod was put inside it and the dish was placed on it.

The stoves were also made of clay and were situated in a row next to each other on the other corner of the cookhouse. The stoves were not movable and when the cookhouse was built, they were placed in the wall. Every stove was made of clay and plaster walls that were situated on the ground in parallel to each other and they were attached to their rear wall. The firewood was put in the middle of these spaces and when the fire was set, they placed the container on its two edges. Because of the different sizes of the containers, the stoves had mainly two sizes, large and small. The cookhouse did not have a water supply and for cooking they used the water from the yard and the dishes were washed in the yard by the pond and were dried by the sun. Serving and eating food and washing the dishes were done in separate places. Therefore, the cookhouse was only a place for cooking and baking. (Picture 1). 
Picture 1. Source: The Author

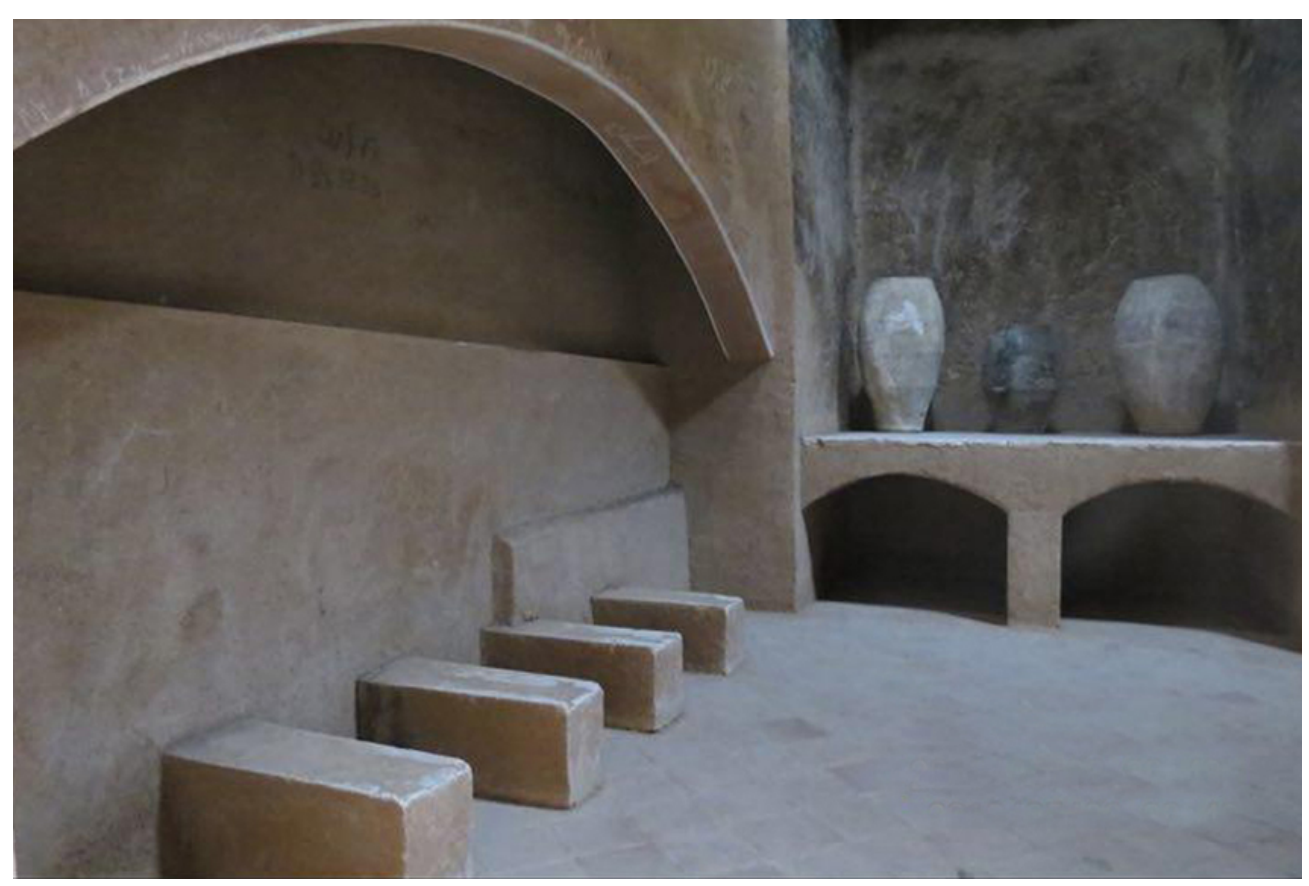

\section{THE KITCHEN}

It is a place for keeping and preparing food. The main activities that take place in the kitchen are cooking, preparing food, washing the dishes andwashing the clothes with the washing machine. It is also a place for having breakfast and the dining table is also in the kitchen. The kitchen plays a major role in the house due to the continuous presence of the lady of the house as well as its direct and indirect use by the other family members. The link that the kitchen has with the other areas of the house including the living room and the guest room is very important. Its ease of access, visual control, acoustics and movement has led these two separate spaces of the house to function properly. In the design of the kitchen, a combination of practical necessities with pleasant spaces is essential (Baden-Powell, 2009). In the division of the interior space of the house which include private, semi-private and public spaces, the kitchen is a semi-private space (KhojastehGhamari, 2010). (Picture 2) 
The Turkish Online Journal of Design, Art and Communication - TOJDAC July 2016 Special Edition

Picture 2. Source: The Author

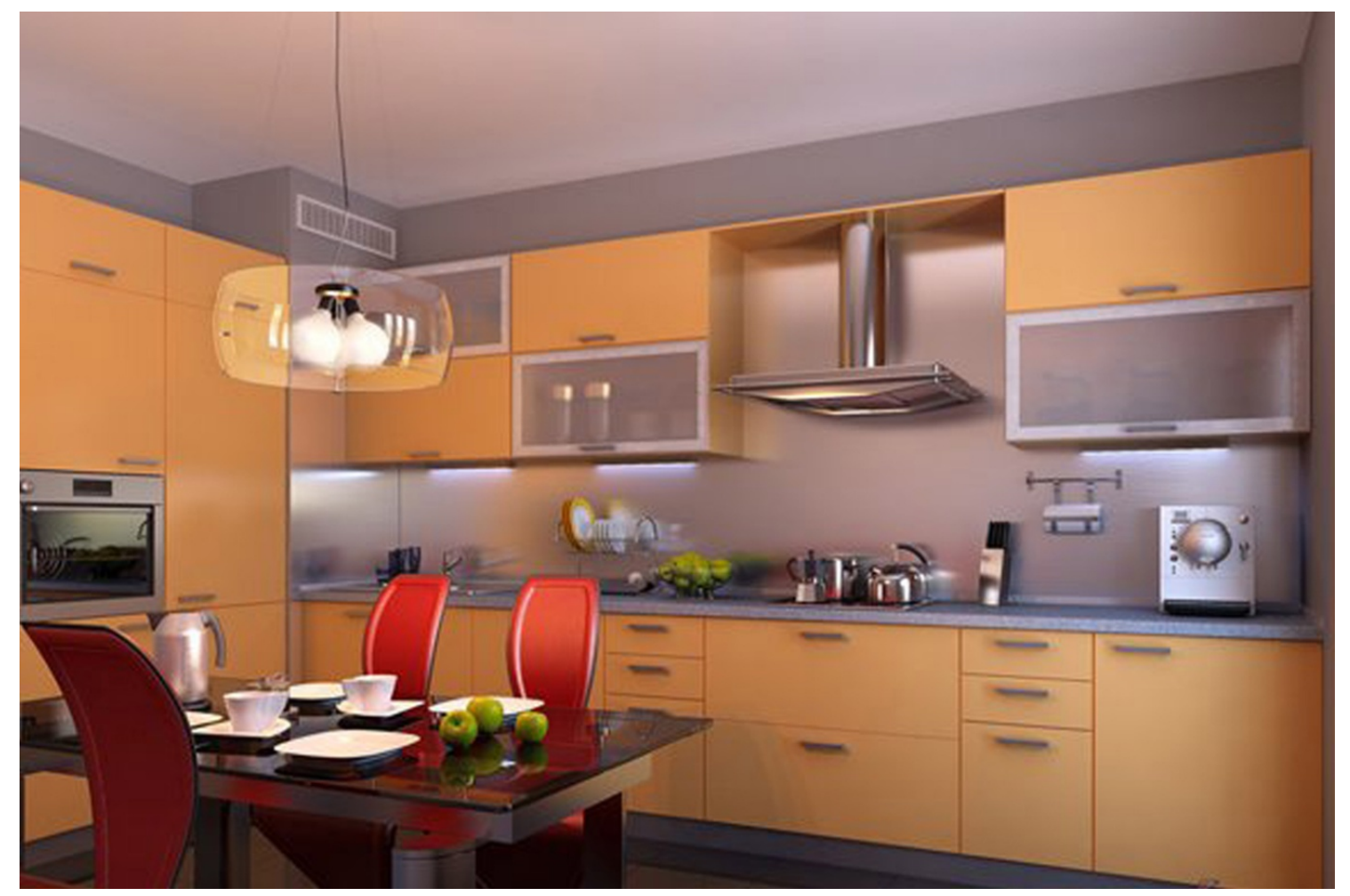

Table 1. The process of relocation of the cookhouse from the yard and the basement to its proximity with the living room (HaeriMazandarani, 2009) 
The Turkish Online Journal of Design, Art and Communication - TOJDAC July 2016 Special Edition

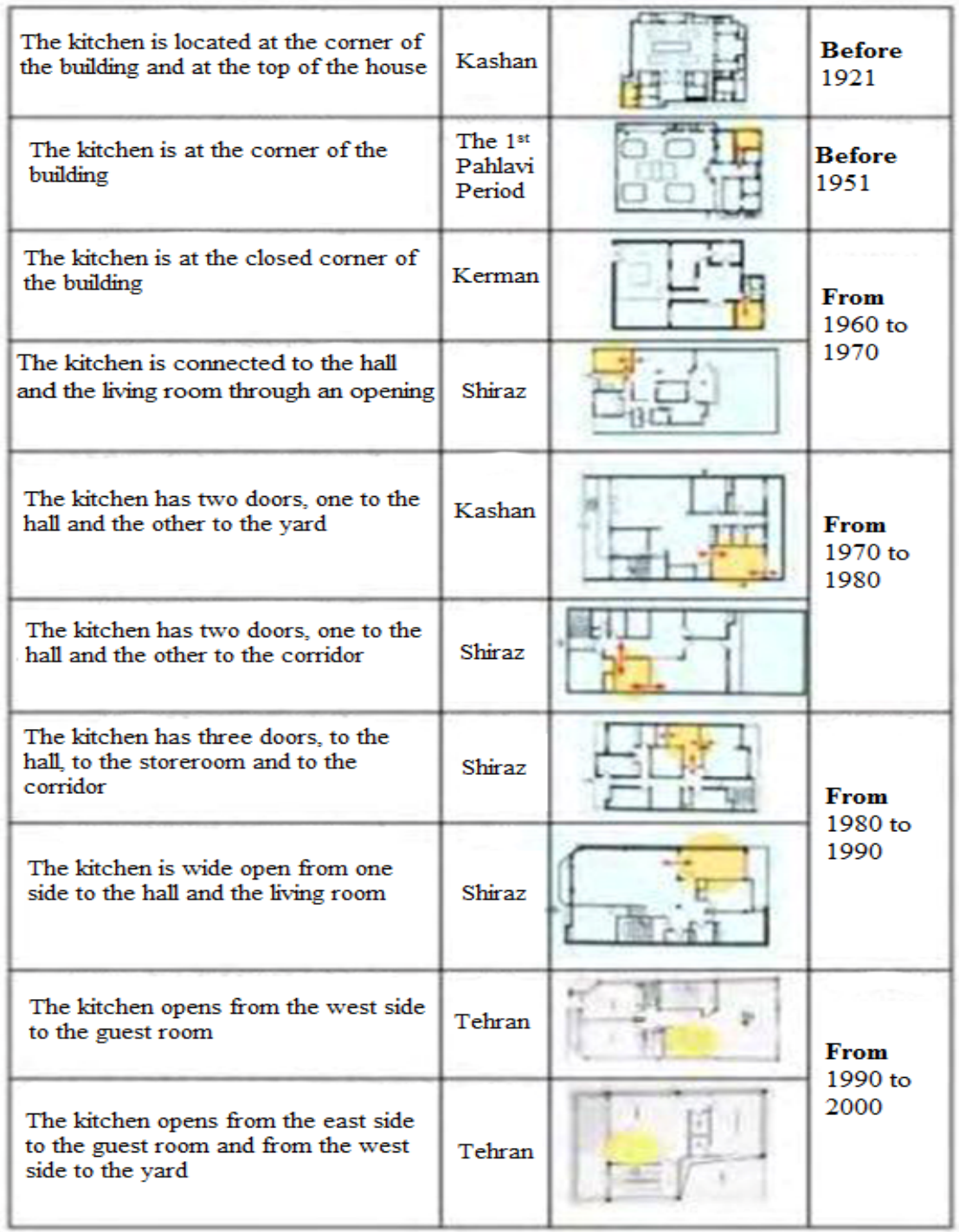

\section{A Review of the Characteristics of the Kitchen and the Cookhouse from 1921 to the 2000s}

\section{BEFORE 1921}

During this time 5 percent of the residential space is allocated to the cookhouse and the building is divided into two parts, welfare and services. The cookhouse is part of the services and access to it, is possible from the yard. Air and light would enter from the openings on the ceiling and it is a place for storage of raw materials. (Diagram 1)
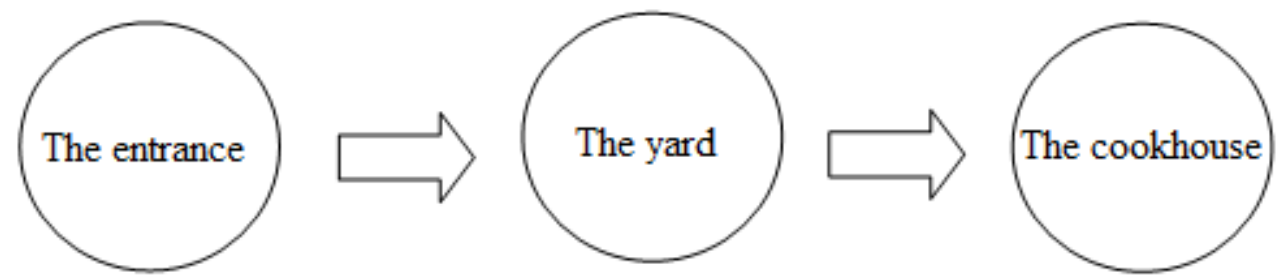

\section{BEFORE 1951}

Submit Date: 10.05.2016, Acceptance Date: 25.06.2016, DOI NO: 10.7456/1060JSE/027

Copyright (C) The Turkish Online Journal of Design, Art and Communication 
Almost 7 percent of the residential space is allocated to the kitchen. This space has a window to the outside of the house for light and ventilation. The cookhouse and other parts of the house would lead to a sub-corridor that is connected to the main corridor and the entrance. The cookhouse has a storage section connected to the main corridor and the entrance for he direct entry of raw materials into the house. (Diagram 2)
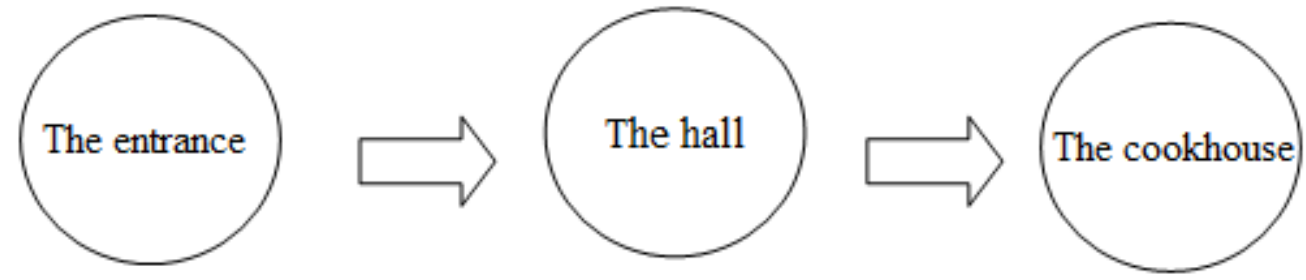

\section{THE 60S}

During this time, the kitchen occupies 12 percent of the building. It has a window to the outside of the house. The kitchen and the other parts of the house are connected through a corridor and also during this time the storage section is omitted from the kitchen. (Diagram 3)
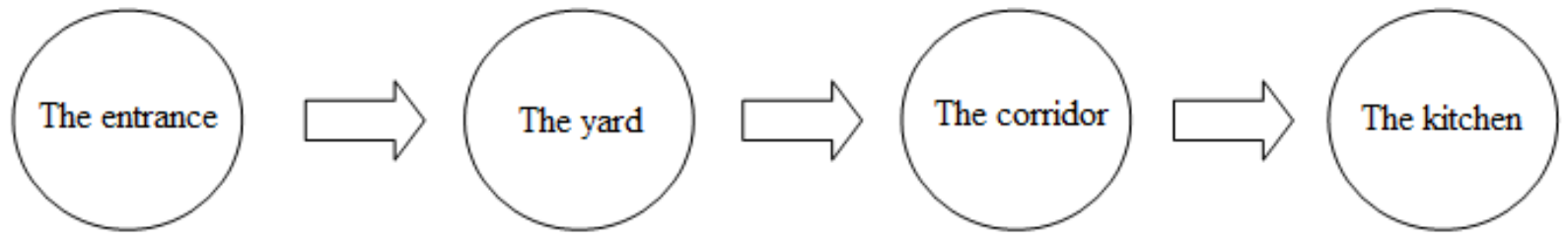

\section{THE 70S}

The kitchen occupies 11.5 percent of the building. However, the range of this space is from 8-19 percent of the area. In all the examined models of this decade, the kitchen space has a direct exposure to light which shows that at least one side of this space is located near the outdoor space. In the study of how to reach the kitchen from the entrance, a communicational corridor is seen in all the models of this decade that links the kitchen to the other parts of the house. The living room is a separate space and thus it rarely happens that the kitchen wall would be open. In most models of this time, there is no direct link between the kitchen and the living room and in only a few instances we see an opening in the kitchen wall and the living room. Therefore, the beginning of the open-style kitchens can be attributed to this decade but still these two spaces are separate and distinct from each other and the only preferred link is through the corridor (Golnia, 2012). (Diagram 4)
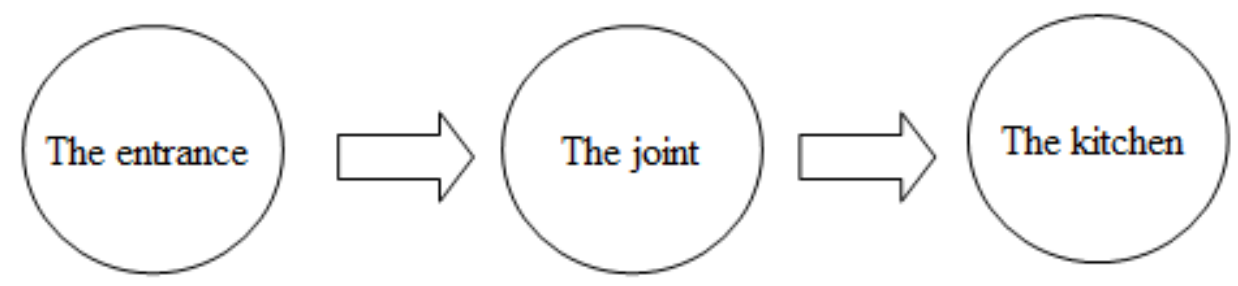

\section{THE 80S}

In this decade, the average space of the kitchen is 13.25 percent of the whole building which is more than the other decades. In very few instances there is an indirect light exposure and in these cases the light either comes from the living room or from a skylight. The opening of the kitchen wall which began from the previous decade can be seen in half of the models of this time. In this decade, contrary to the previous decades in which there was a specific design to reach the kitchen, there are several designs for reaching the kitchen. Generally, passing the spaces like the corridor (17 percent), the joint (17 percent), the living room (44 percent) and entering the kitchen directly after the entrance ( 22 percent), show the variety of 
this path in this decade. Lack of access to the yard and an outside space is one of the disadvantages of the kitchens in this decade (Golnia, 2012). (Diagram 5)

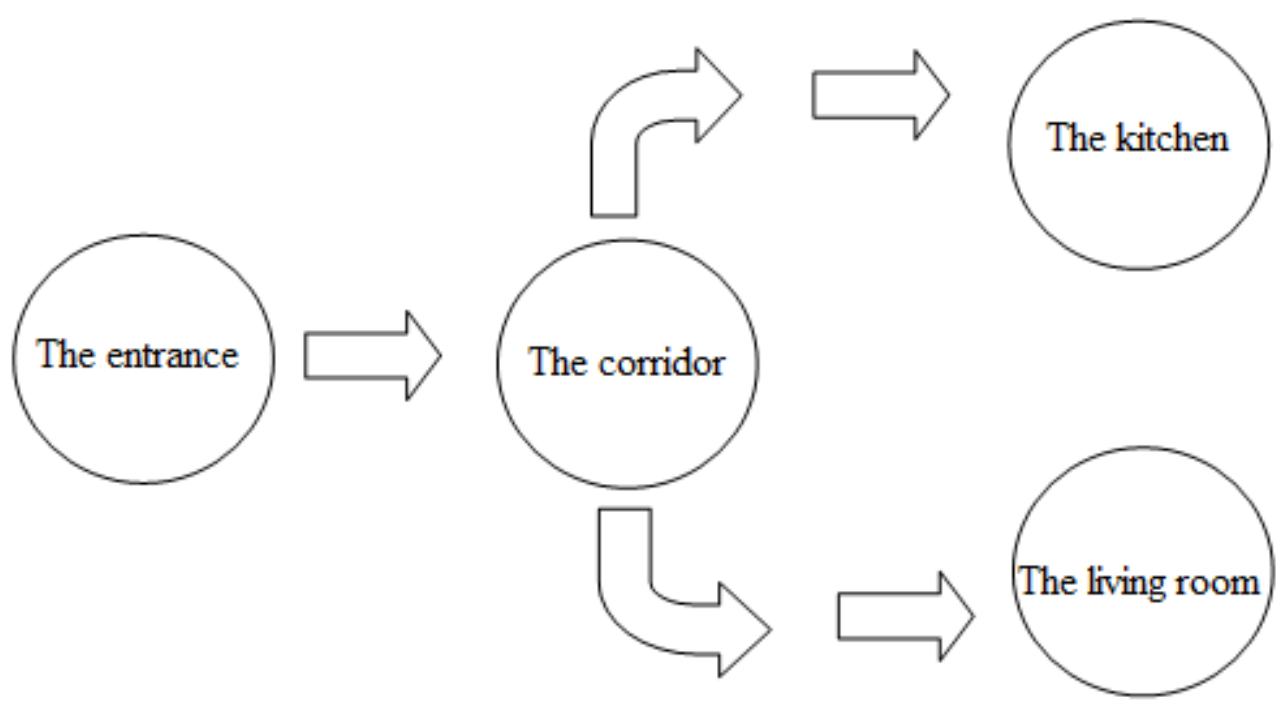

\section{THE 90S}

In this decade the kitchen space does not have a significant change in comparison with the previous decade and is about 13.56 percent of the whole space. Still, in a few instances there is an indirect light exposure but most of the light comes directly. There is an increase of design in this period, thus we cannot recognize a specific design for this period. In this decade there are different ways to pass from the living room to reach the kitchen. Due to this process the living room is not as separate as before, either because of the open style of the kitchen or because the two spaces are connected with a door. What is important in this decade is that except a few instances, we encounter an open-style kitchen facing the living room and this shows a prevalent design in this decade. The problem of lack of connection with the yard and an outside space still exists (Golnia, 2012). (Diagram 6)

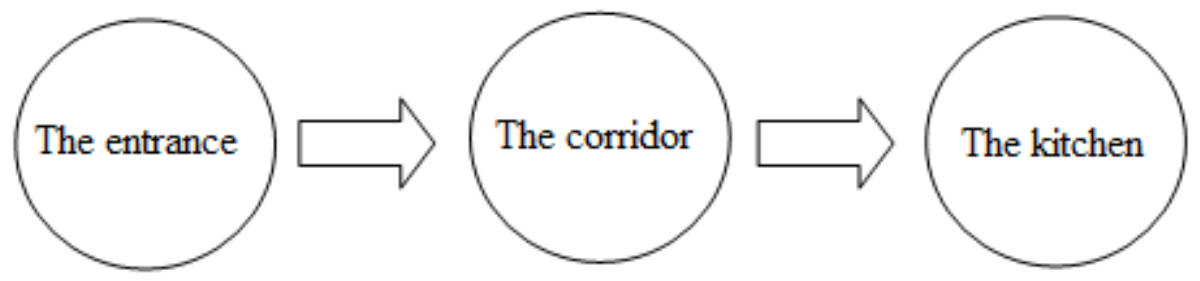

\section{THE 2000S}

In this decade the reduction of the kitchen space is the result of the reduction of the house space. So that the models show an average space of 11 percent from the whole space. The models of this decade show an area of 5-6 square meters. In this decade, the ways that the kitchen is exposed to light varies from the previous decades. In this period, half of the kitchens are directly and the other half are indirectly exposed to light. There is a variety of patterns from the entrance to the kitchen so that we cannot recognize a certain pattern for this period. However, in most cases the kitchen is situated right after the entrance. In this way the living room and the kitchen have an equal importance after the entrance. In almost every model, one of the kitchen walls opens to the living room and in other cases this wall is omitted and the two spaces become one. Its connection with the outdoor space is through the terrace; thus a lack that existed in the previous decades was resolved in this decade (Golnia, 2012). (Diagram 7) 


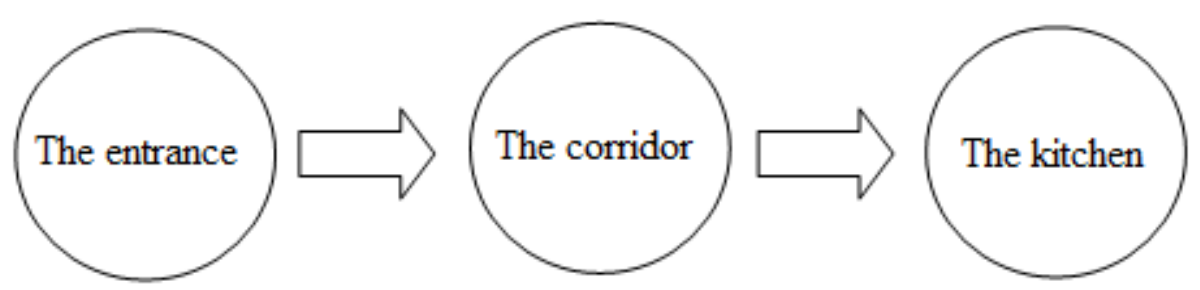

THE PROPORTION OF THE KITCHEN SPACE TO THE TOTAL SPACE

The proportions of the kitchen space to the total space over different periods were determined by examining the models and the results are shown in the chart below. (Chart 1)

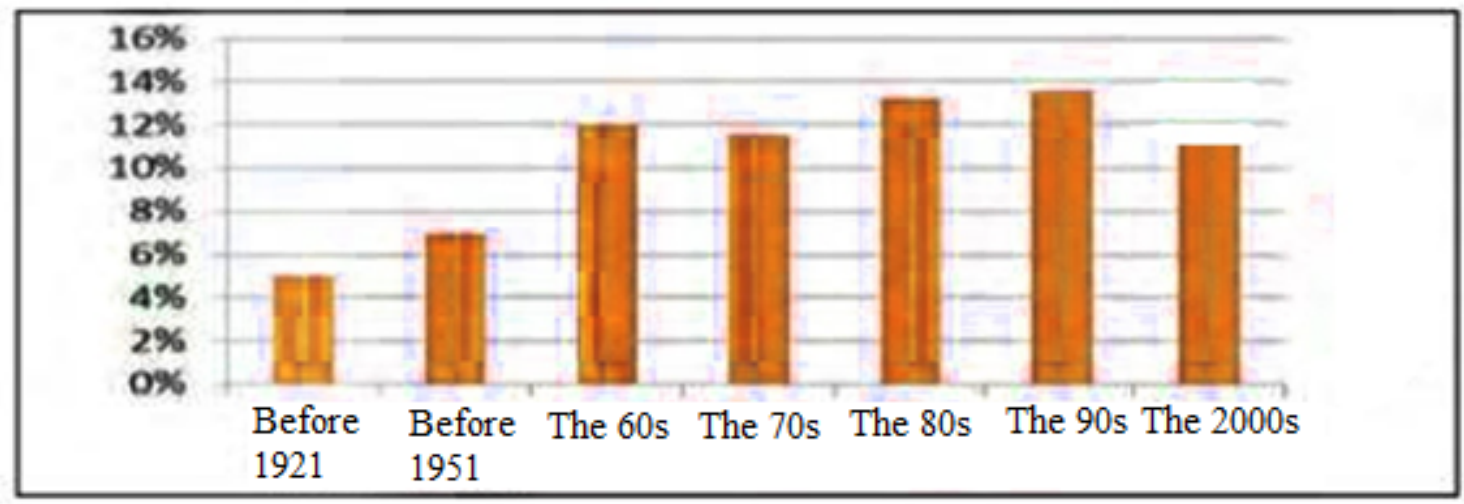

\section{THE ROLE OF TECHNOLOGY IN THE EVOLUTION OF THE COOKHOUSE TO THE KITCHEN}

In the period of transmission and transformational facilities related to the house, technology has a role in organizing the space and the physical form of the house. After the industrial revolution and the spread of machinery, a great change occurred in the design of the kitchen. For example, the use of oil and gas for home heating and cooking have led the cooking activities to become clean and fast.As a result, the kitchen becomes a relatively clean space, although in these buildings, the cooking space could not quickly change, but its means were provided (SoltanZade, 2002). So it can be concluded that the industrial revolution and the improvement of western architecture and the great technological changes, had an important role in this evolution.

\section{CONCLUSION}

Privacy is one of the fundamental principles governing the universe and its phenomena. Its impact on the physical and spatial structure of traditional Iranian architecture is undeniable. The results show that with the advent of new technologies such as gas and piped water, a sub-space (a cookhouse) turns into a multipurpose space (a kitchen). In the past there was no direct link between the kitchen and the living room and they were connected from the entrance of the kitchen facing the living room. Although these two spaces are separate, in order to enter the kitchen one has to pass the living room. So it can be concluded that in modern houses, the privacy of the two separate areas have been violated. It can be noted that the little remaining privacy from the traditional Iranian architecture has faded. Although this evolution has brought relief to architecture and in the last century has quickly reached its pinnacle, it may not be consistent with our culture and social attitudes and would be in conflict with our traditional architectural values. Perhaps with a shift in the design of modern houses and apartments, a slight veil of privacy can be added to these developed spaces. 


\section{REFERENCES}

HaeriMazandarani, Mohammad Reza, 2009, "House, Culture, Nature: A Historical and Contemporary Study of the House to Develop a Process of House Designing", Publishing Research Center for the Study of Urban Planning and Architecture, Tehran.

SoltanZadeh, Hosein, 2002, "From House to Apartment", Architecture and Culture Quarterly, Seventh Year, No. 23.

Baden-Powell, Charlotte, 2009, The Kitchen Design, Translated by Mohammad Reza Shahi, Yazda Publishing.

Kateb, Fatemeh, 2005, Iranian House Architecture, Ministry of Culture and Islamic Guidance Publishing, Tehran.

Dictionary of Dehkhoda.

Golnia, TaherehGol, 2012, "The Kitchen and Its Place in the Contemporary House", National Conference on a Century of Iranian Architecture and Urbanism, Karaj, Engineering Organization of Alborz Province. Ghaderi, Himan, 2012, "The Evolution of the Kitchen in Iranian Residential Spaces", The First National Conference on New Ideas and Technologies in Architecture, Tabriz, Society of Tabriz Architects.

KhojastehGhamari, Mohammad Amin, 2010, A New Approach to the Kitchen Design, Architecture and Culture, Twelfth Year, No.40, p. 82. 